\title{
Cultura, turismo e desenvolvimento: reflexões acerca do potencial arqueológico no município de Carnaúba dos Dantas (RN)
}

\author{
Culture, tourism and development: insights \\ on the potential exploration of archeological rock art in \\ Carnaúba dos Dantas (RN, Brazil)
}

\author{
Wilker Ricardo de Mendonça Nóbrega, Francineide Araújo
}

\section{RESUMO}

O principal objetivo deste trabalho é identificar as possibilidades e entraves para o desenvolvimento do turismo arqueológico na região do Seridó Potiguar, sobretudo no município de Carnaúba dos Dantas. O turismo arqueológico quando planejado e organizado pode ser um instrumento capaz de proteger, promover e potencializar o patrimônio arqueológico de uma determinada região. A metodologia do trabalho constituiu-se de um estudo exploratório, realizado por meio de duas pesquisas, a pesquisa bibliográfica, envolvendo conceitos associados à temática em questão, e em seguida, a segunda etapa caracterizou-se de um levantamento de dados por meio de uma pesquisa de campo, utilizando-se como instrumentos de coleta de dados, a observação direta, entrevistas e registro fotográfico. Os resultados apontaram que Carnaúba dos Dantas apresenta um significativo potencial para o desenvolvimento do turismo arqueológico, dentre elas a existência de atrativos que podem ser planejados para visitas organizadas de forma sistemática. Todavia, evidenciou-se como principal entrave para o desenvolvimento deste segmento turístico a falta de conhecimento e informação dos proprietários das áreas rurais acerca da relevância histórica e cultural dos registros rupestres. Acredita-se que se o segmento do turismo arqueológico for trabalhado de forma sinérgica entre os atores públicos, privados e do terceiro setor, a região poderia ter uma outra alternativa econômica além da pecuária, agricultura e mineração.

PALAVRAS-CHAVE: Desenvolvimento Turístico; Patrimônio Cultural e Arqueológico; Carnaúba dos Dantas. 


\section{ABSTRACT}

The primary objective of this study was to identify opportunities and bottlenecks for the development of archeological tourism in the Serido Potiguar region, particularly in the municipality of Carnaúba dos Dantas. Archeological tourism, when well planned and organized, can serve as an instrument for protecting, promoting and potentiating the archeological heritage of a determined region. The methodology used in this study consisted of a literature review involving concepts associated with the topic in question, followed by a second phase involving data collection through fieldwork using the following data collection methods: participant observation, semi-structured interviews and photographic recording. The results indicate that there is a significant potential in Carnaúba dos Dantas to develop archeological tourism such as the existence of attractions that can be planned for organized visits in a systematic way. By contrast, it was observed a lack of knowledge and information among residents of the rural area in respect to the historical and cultural relevance of the rock art and this represents the primary bottleneck to development of this tourism segment. These findings suggest that, if the archeological tourism segment is approached in synergy among public, private and third party stakeholders, it could serve as an economic alternative to cattle raising, agriculture and mining for residents of the region.

KEYWORDS: Tourism Development; Cultural and Archeological Heritage; Carnaúba dos Dantas.

\section{Introdução}

O acesso de um quantitativo expressivo de viajantes está associado ao desenvolvimento dos transportes, principalmente após a Primeira Guerra Mundial, quando o turismo foi impulsionado pela abertura de ferrovias, inicialmente na Europa e posteriormente na América do Norte. Paulatinamente, o setor turístico tomou uma grande proporção que possibilitou o surgimento de novos nichos de mercado que se contrapusesse ao modelo massivo, predominante nos discursos das agendas públicas e da disponibilidade de produtos oferecidos pelas empresas que atuavam no mercado turístico até meados da década de 1970 (FIGUEIREDO, 2010).

O processo de propagação da atividade turística conseguiu consolidar-se não somente em função do fortalecimento de um "simples capitalismo", mas de um capitalismo de forma globalizado, ou seja, neste período depara-se com o termo globalização da economia, período este caracterizado pela nova forma gerada nas últimas décadas pelo processo de acumulação e internacionalização do capital além das restrições crescentes que seu funcionamento e suas forças dominantes (corporações transnacionais e detentores do capital financeiro) impõem à soberania e à autonomia dos Estados nacionais (NÓBREGA, 2012).

Com o crescimento do turismo, observou-se também a existência de diferentes enfoques, tendo em vista as diversas motivações e interesses dos turistas, as quais abrem oportunidade para o desenvolvimento de vários segmentos, dentre eles o denominado turismo arqueológico ou arqueoturismo, cujos atrativos são os recursos do patrimônio arqueológico 
os quais são otimizados pela atividade para visitação. De acordo com Manzato e Rejowski (2005), o turismo arqueológico é um segmento que vem apresentando um crescimento e desenvolvimento nos últimos anos, o qual pode ser identificado por meio da quantidade de sítios arqueológicos disponíveis para visitação. O turismo arqueológico não é mais restrito a lugares como Grécia e Egito, ele tem sido desenvolvido em vários países do mundo, inclusive no Brasil.

Nesse sentido, percebe-se que atualmente diversos países possuem o turismo ligado às questões arqueológicas como fonte de desenvolvimento socioeconômico, e o número de visitantes que buscam entrar em contato com o seu passado por meio dessa prática vem aumentando cada vez mais Manzato e Rejowski (2005). Diante do exposto, o principal objetivo deste trabalho é discutir a relação entre turismo arqueológico e desenvolvimento regional, sobretudo no município de Carnaúba dos Dantas, Estado do Rio Grande do Norte, Brasil.

O texto está dividido em três seções distintas. A primeira abordará questões referentes à cultura, turismo e desenvolvimento. A segunda seção discutirá temas referentes ao turismo e patrimônio arqueológico como elementos fomentadores e estimuladores do desenvolvimento. A última seção abordará o potencial e os fatores limitantes do desenvolvimento do turismo arqueológico na região do Seridó Potiguar, sobretudo no município de Carnaúba dos Dantas.

O trabalho justifica-se, pois a literatura disponível sobre o turismo arqueológico aponta que quando o segmento é planejado, ele pode atuar como um instrumento capaz de proteger, promover e potencializar o patrimônio arqueológico. Sendo assim, observa-se que o turismo arqueológico pode desempenhar uma função relevante para a sociedade. Do ponto de vista científico, a pesquisa tem relevância, pois com base na revisão de literatura realizada para o desenvolvimento deste trabalho constatou-se a existência de poucos estudos acadêmicos abordando esta temática em virtude do turismo arqueológico ser um segmento ainda pouco trabalhado tanto por empresas turísticas, quanto pelos cursos de turismo nas universidades brasileiras.

Os procedimentos metodológicos empregados abrangeram uma revisão de literatura e pesquisa de campo. Os estudos bibliográficos foram baseados na leitura de livros, artigos, monografias de graduação, dissertações de mestrado e teses de doutorado que versavam sobre a temática em questão. Outro recurso utilizado foi a pesquisa de campo, para isso foi utilizada as técnicas de observação direta, entrevistas e registro fotográfico. As entrevistas foram realizadas com o poder público municipal, estadual e federal e moradores que residem no entorno de sítios arqueológicos no município de Carnaúba dos Dantas, localizado no sertão do Estado do Rio Grande do Norte.

Diante do que foi pesquisado, acredita-se que se faz necessário cada vez mais desenvolver trabalhos ligados ao patrimônio arqueológico, pois apesar da grande potencialidade dos recursos disponíveis para 0 desenvolvimento das regiões a partir do uso do patrimônio arqueológico, também é importante destacar que o patrimônio está ameaçado em virtude 
da própria deterioração natural decorrente da ação do tempo (chuva, sol, entre outros), e pela possibilidade de depredação dos sítios em virtude do acesso inadequado de curiosos aos locais detentores de pinturas e gravuras rupestres; e pela ausência de política pública nos municípios que estabeleça diretrizes para a conservação e preservação do patrimônio.

\title{
Cultura, turismo e desenvolvimento regional
}

A lógica do desenvolvimento regional, aliada ao estímulo de uma relativamente nova atividade econômica, o turismo, tem dado à diferentes regiões brasileiras e seus municípios novos arranjos e configurações sócioeconômico-espaciais. Diante disso, o poder público vem planejando e gerenciando o setor a fim de proporcionar o desenvolvimento de diferentes regiões, dadas as particularidades paisagísticas, climáticas, da demanda de visitantes, no intuito de garantir melhoria na qualidade de vida, tanto para residentes quanto para visitantes, e a tessitura urbana, também influenciada por esta atividade, vem ganhado conformações diferentes dos seus originais, e inversão de valores econômicos e espaciais também diferentes dos construídos anteriormente, sobretudo com a entrada da dimensão estética e infraestrutural no planejamento (NÓBREGA, 2012).

Geralmente quando se reporta ao conceito de região como espaço natural, há uma associação direta da contribuição dos estudos geográficos, principalmente quando se trata da geografia física onde a paisagem, por exemplo, é uma categoria importante nesse arcabouço teórico. Por outro lado, a geografia humana se utiliza de aspectos sociológicos, históricos, políticos, culturais e econômicos para a definição de conceitos mais amplos. Diante disso, é visível que os critérios de definição têm divergências, então, seria mais oportuno pensar na definição de região como um parâmetro que ao mesmo tempo tem um ar de concretude, mas também um alto grau de abstração onde diferentes atores sociais criam laços econômicos, culturais e políticos a partir de relações geradas por fatores internos e externos a este espaço, e que deve ter uma abordagem multidisciplinar (NÓBREGA, 2012). Para esta compreensão é necessário uma visão ampla, sistêmica da regionalização como processo. Nesse processo pesa, a constatação de identidades internas, mas pesa, igualmente, o deslocamento produzido pelas diferenças provenientes do mundo externo. De acordo com Corrêa (1986, p. 45), região é conceituado como:

\begin{abstract}
Uma entidade concreta, resultado de múltiplas determinações, ou seja, da efetivação dos mecanismos de regionalização sobre um quadro territorial já previamente ocupado, caracterizado por uma natureza já transformada, heranças culturais e materiais e determinada estrutura social e seus conflitos.
\end{abstract}

A carga simbólica e abstrata intrínseca ao conceito de região condicionou a uma transformação e, ou, atualização a partir dos eventos ocorridos em escala global. A internacionalização do capital produtivo, 
paralela à fase técnico-científica, veio por à mostra a debilidade do conceito pelo menos em sua noção clássica. De acordo com Santos (2008, p.90), a região se definiria como "resultado das possibilidades ligadas a uma presença, nela, de capitais fixos exercendo determinado papel ou determinada função técnica e das condições do seu funcionamento econômico, dadas pela rede de relações acima indicadas". Ainda de acordo com Santos (2008), o momento atual vivido pelas nações, onde a interação entre as regiões produtivas de um estado ou do país como um todo são um aspecto fundamental na compreensão do funcionamento do território.

O aspecto regional seria configurado pelas formas explicitadas a pouco pelo autor exatamente por tais formas, consideradas, porém, como formas-conteúdo e não como formas vazias. De fato, os fixos na qualidade de formas técnicas, exceto se já não funcionam, jamais deixam de serem portadores de um conteúdo, isto é, de um sistema de relações ligado à lógica interna de firmas ou instituições e que opõe resistências à lógica mais ampla, de natureza geral, nacional (SANTOS, 2008).

As estratégias governamentais de constituir aglomerados empresariais regionais, arranjos produtivos locais e, pólos turísticos são algumas das ações deliberadas por gestores públicos e privados no intuito de garantir uma maior produtividade e qualidade no produto e, ou, serviço oferecido para gerar o desenvolvimento regional. São inegáveis os resultados financeiros decorrentes do turismo, justificando a inclusão da atividade na programação político-econômica de todos os países que o adotaram como uma alternativa de desenvolvimento. Os inúmeros eventos recorrentes nas últimas décadas adotados pelo Governo Federal Brasileiro, materializados na forma de programas, planos e projetos começaram a tomar corpo, por exemplo, na região do Seridó Potiguar a partir da criação de uma instância de governança do polo turístico do Seridó, porém ainda sem resultados concretos efetivados.

Para Perroux (1967), a perspectiva de desenvolvimento regional está associada ao conceito de polo de crescimento. Para o autor, um dos aspectos das mudanças estruturais que deve ser considerado, consiste no aparecimento e desaparecimento de indústrias no fluxo do produto industrial global, ao longo de períodos sucessivos e nas taxas de crescimento diferentes para as diferentes indústrias, ao longo de um mesmo período ou de períodos sucessivos. Com a aglomeração industrial-urbana surgem tipos de consumidores com padrões de consumo diversificados e progressivos, em comparação com os do meio rural. Necessidades coletivas como a habitação, transportes, serviços públicos emergem e se encadeiam. Rendas da terra vêm somar-se aos lucros dos negócios. No âmbito da produção, tipos de produtores como empresários, trabalhadores qualificados, quadros industriais formam-se e mutuamente se influenciam, criam suas tradições e eventualmente participam do espírito coletivo.

As discussões acerca do desenvolvimento regional colocam em pauta a colaboração de diferentes linhas de pensamento, seja numa perspectiva econômica, social, espacial, entre outras que se entrelaçam na condição sine qua non na estruturação do modus vivendi de qualquer nação. Nesse contexto, de um conjunto de diferentes atividades importantes para atingir um nível de desenvolvimento é que se destaca o setor turístico. 
A mudança na realidade do mercado turístico tornou a demanda mais exigente, diversificada e hostil aos ambientes massificados, adquirindo assim novos hábitos e motivações (FIGUEIREDO, 2010). Em virtude das novas tendências impostas pelo mercado, a atividade turística passou a sentir necessidade da utilização da segmentação de mercado como estratégia para conhecer e estudar o mercado turístico formado por consumidores com necessidades, gostos, interesses, preferências e desejos diferenciados. Segundo Barreto e Rejowski (2009, p. 04), "até a década de 1970 a literatura parecia reconhecer apenas o turismo, uma atividade indiferenciada, e o turista, uma espécie de ser genérico também indiferenciado".

A utilização das técnicas de segmentação do mercado turístico possibilitou a criação de uma oferta bastante diversificada para a atividade composta por modalidades que têm atraído públicos diferenciados, motivados por interesses afins. Dentre os segmentos turísticos existentes na atualidade estão: turismo rural, de aventura, pedagógico, de eventos, de negócios, ecoturismo e o turismo arqueológico.

O turismo arqueológico, foco deste trabalho, está associado diretamente ao contexto cultural da sociedade. A temática cultural tem norteado grandes discussões, surgindo assim interesses interdisciplinares, sendo estudada em áreas como sociologia, antropologia, história, comunicação, administração, economia e turismo. Em cada uma dessas, existem concepções e maneiras distintas de entender o que é cultura. Nesse sentido, ela é trabalhada a partir de diferentes enfoques e usos.

A origem etimológica da palavra cultura advém do termo latino colere, $e$ inicialmente esteve relacionado ao cultivo, o cuidado com a terra. No século XVIII, sob a influência do período iluminista, esse sentido assume outro contexto, e cultura torna-se sinônimo de civilização. Por esse motivo, passa a ser considerada condição, critério para medir o grau de civilização de uma sociedade. A esse conceito foi adicionada a ideia de tempo, de evolução, tornando-se assim sinônimo de progresso. "Avalia-se o progresso de uma civilização pela sua cultura e avalia-se a cultura pelo progresso que traz a uma civilização" (CHAUí, 2008, p.55).

Ainda de acordo com a autora, no século XIX, com o surgimento da antropologia, a ideia de cultura como progresso e evolução inicialmente permanece. No entanto, estabelece-se um padrão para medir essa evolução, adotando assim, o da Europa capitalista. Nesse contexto, o grau de evolução ou de progresso das sociedades passou a ser medido por meio dos seguintes elementos: o estado, o mercado e a escrita. Ainda nesse século, a noção de cultura sofre uma alteração sob a influência, principalmente, da filosofia alemã, passando a ser idealizada como diferença entre natureza e história. "A cultura é a ruptura da adesão imediata a natureza, adesão própria aos animais, e inaugura o mundo humano propriamente dito" (CHAUÍ, 2008, p.55).

Dessa forma, percebe-se que a cultura ao ser utilizada no início do século XIX como meio para medir o grau de progresso ou de evolução de uma sociedade acabou se tornando uma forma de discriminação, a qual ocasionava exclusões. Todavia, no momento em que ocorreu a 
diferenciação entre natureza e história ela passou a ser entendida com uma amplitude maior, como parte de um processo histórico, independente do lado biológico humano.

No entanto, a visão cultural em um sentido mais stricto considera como cultura atividades mais específicas realizadas pelo homem, ligadas diretamente ao seu intelecto, à busca do conhecimento, como a arte, a ciência, o esporte e a religião. Nessa segunda concepção de cultura, ela estaria mais ligada aos bens espirituais da espécie humana. Nesse sentido, percebe-se que o conceito de cultura é influenciado por elementos subjetivos, por isso é um termo considerado complexo e abrangente.

A discussão sobre a cultura, hoje, também é uma preocupação de planejadores, não somente no universo turístico em escala mais macro, mas também em determinados segmentos desta atividade, como o turismo arqueológico. A seguir será apresentada uma discussão acerca do potencial brasileiro voltado ao turismo arqueológico, sobretudo na região do Seridó Potiguar.

\section{Turismo e patrimônio arqueológico}

O Brasil é um país com grande potencial para o desenvolvimento do turismo arqueológico, pois possui um diversificado patrimônio arqueológico representado pelos inúmeros sítios arqueológicos existentes. De acordo com o Instituto do Patrimônio Histórico e Artístico Nacional, IPHAN (2011), atualmente cerca de 19 mil sítios arqueológicos já foram identificados no país.

O termo patrimônio, em virtude das mudanças ocorridas na sua conceituação nos últimos anos pode assumir sentidos diversos. A princípio o termo esteve relacionado à herança familiar, voltada mais para bens materiais. A partir do século XVIII, na França, o poder público teve as primeiras iniciativas em estabelecer medidas de proteção aos monumentos que tivessem valor para a história das nações, então, o seu uso estendeu-se para bens protegidos por lei, e pela ação dos órgãos constituídos foi nomeado bens culturais de uma nação (FUNARI, 2005; FIGUEIREDO; NÓBREGA, 2012).

Conforme os autores citados, com a criação dos patrimônios nacionais a qual se intensificou no século XIX, o patrimônio passou a ser de "uma coleção simbólica unificadora, que procurava dar base cultural idêntica a todos, embora os grupos sociais e étnicos presentes em um mesmo território fossem diversos" (FUNARI, 2005, p.16). Os autores mencionam ainda que nesse contexto, o patrimônio assume uma extrema importância política. Sendo assim, a palavra patrimônio indicava uma escolha oficial, motivo pelo qual envolvia exclusões.

Então, percebe-se que a proteção do patrimônio nesse período tinha um caráter elitista, ou seja, preservava-se o que fosse de interesse da classe dominante. Assim, o conceito de patrimônio ganhou uma abrangência muito limitada, porque contemplava apenas os bens materiais.

Para Silva (2008), a concepção sobre patrimônio possui relação com o sentido de pertencimento, de posse, atribuindo-o valor relativo, variando de 
acordo com as pessoas e os grupos ao longo do tempo. Deste modo, observa-se que a palavra patrimônio está sujeita a escolhas, pois, ao longo dos anos veio adquirindo novos sentidos, tendo em vista que cada sociedade, dependendo do contexto histórico a qual está inserida, elege o que quer considerar como patrimônio. De acordo com Barreto (2000, p.09) praticamente até a metade do século XX "o patrimônio cultural foi sinônimo de obras monumentais, obras de arte consagradas, propriedades de grande luxo, associadas às classes dominantes, pertencentes à sociedade política ou civil'.

A partir da década de 1970, o conceito de patrimônio cultural passou a ser visto de forma mais abrangente, incluindo não apenas os bens culturais materiais. Nesse contexto, os bens de natureza imaterial passaram a ser adicionados ao conceito de patrimônio cultural. É essencial destacar nesse cenário no âmbito mundial, a Conferência do México sobre políticas culturais organizada pela Organização das Nações Unidas para a Educação, a Ciência e a Cultura (UNESCO) em 1985, e em âmbito nacional a Constituição Federal Brasileira, que adotou essa nova concepção sobre patrimônio cultural Costa (2009). De acordo com a Constituição Federal Brasileira de 1988, art. 216, consideram-se Patrimônio Cultural Brasileiro os:

\footnotetext{
Bens de natureza material e imaterial, tomados individualmente ou em conjunto, portadores de referência à identidade, à ação, à memória dos diferentes grupos formadores da sociedade brasileira, nos quais se incluem:

I - as formas de expressão;

II - os modos de criar, fazer e viver;

III - as criações científicas, artísticas e tecnológicas;

IV - as obras, objetos, documentos, edificações e demais espaços destinados às manifestações artístico-culturais;

$V$ - os conjuntos urbanos e sítios de valor histórico, paisagístico, artístico, arqueológico, paleontológico, ecológico e científico.
}

Nesse sentido, compreende-se que patrimônio cultural é tudo aquilo que é representativo, possui significado para um determinado povo, não está relacionado apenas aos aspectos materiais, arquitetônicos, como monumentos, prédios históricos, obras de arte, mas, inclui também elementos imateriais como: as manifestações populares, as festas, danças, o saber fazer, entre outros.

Na reflexão sobre patrimônio é pertinente fazer a distinção conceitual de dois termos relacionados à sua forma de proteção: preservar e conservar. De acordo com Barreto (2000, p.15):

Preservar um patrimônio significa proteger, resguardar, evitar que alguma coisa seja atingida por outra que lhe possa ocasionar dano [...]; preservar o patrimônio implica mantê-lo estático, intocado; conservar significa "manter, guardar para que haja uma permanência no tempo, [...] integrá-lo no dinamismo do processo cultural". 
Assim, fica claro que há uma distinção entre esses termos. Preservar significa manter as condições originais do patrimônio sem realizar nenhum tipo de alteração. No entanto, a conservação é o uso racional dos recursos permitindo sua manutenção ao longo do tempo. Dessa forma, percebe-se que o termo conservar é o mais adequado a ser utilizado pelo turismo, pois diz respeito àquelas áreas que possibilitam a visitação pública e a prática de determinadas atividades aliadas ao uso e manutenção adequada dos espaços. Já a preservação diz respeito a áreas impossibilitadas à visitação, ou seja, são intangíveis para o visitante, e nenhuma possibilidade de visitação é oferecida.

O patrimônio cultural como visto anteriormente na sua conceituação, constitui-se de bens materiais e imateriais. De acordo com o IPHAN (2011), o patrimônio material é composto pelo conjunto dos bens culturais (arqueológico, paisagístico e etnográfico; histórico; belas artes e artes aplicadas). Esse tipo de patrimônio é dividido em duas categorias: bens culturais imóveis, dentre os quais fazem parte os núcleos urbanos, sítios arqueológicos e paisagísticos e bens individuais; e bens culturais móveis, como coleções arqueológicas, acervos museológicos, documentais, bibliográficos, fotográficos, entre outros. Assim, entende-se que o patrimônio material abrange todos os bens culturais tangíveis, palpáveis, sejam estes móveis ou imóveis.

Dentre os diversos segmentos do turismo existentes na atualidade, tem-se destacado em cenário mundial nos últimos anos, o arqueoturismo, o qual resulta da união entre o turismo e a arqueologia, demonstrando assim a relação entre essas duas áreas aparentemente tão distintas. Para Horta, Grumberg, e Monteiro (1999, p. 32), "a arqueologia é a ciência que nos permite conhecer o passado do homem, antes dos registros históricos. A palavra vem do grego Archaios e do sufixo logia que significa o estudo de alguma coisa". Na concepção de Funari (1998, p.22) a arqueologia, estuda, portanto:

\begin{abstract}
Os sistemas socioculturais, sua estrutura, seu funcionamento e sua transformação no decorrer do tempo através de uma leitura particular, pois seu texto não é composto de palavras, mas de objetos concretos, que em geral são mutilados e deslocados do seu local de utilização original.
\end{abstract}

Então, compreende-se que a arqueologia é uma ciência voltada para a produção do conhecimento. Por meio de suas pesquisas é possível saber como viviam os ancestrais e quais as diferentes formas construídas de organização social.

Para Scatamacchia (2005, p.19), "a arqueologia é uma ciência social que estuda os antigos processos históricos a partir dos vários tipos de vestígios materiais deixados pelos homens". Logo, a arqueologia, ao encontrar os vestígios deixados por civilizações passadas através de escavação, consegue interpretá-los e descobrir como se constituíam essas sociedades e a cultura dessas pessoas. Ainda para a autora, há um entrave 
na difusão do conhecimento arqueológico no que diz respeito à forma como esse conhecimento é apresentado ao público. Geralmente, o meio de divulgação das pesquisas arqueológicas são as disciplinas de graduação e pós-graduação do curso de arqueologia. Portanto, atingem um público específico, restrito. Outro veículo de divulgação desse conhecimento são os documentários nos canais televisivos por assinatura. No entanto, o público que possui esse tipo de canal por assinatura também é reduzido.

A arqueologia, por meio de suas pesquisas gera o conhecimento sobre os achados arqueológicos, matéria-prima para o desenvolvimento do segmento denominado turismo arqueológico. Consequentemente, esse tipo de turismo promove por meio da visitação, o acesso a esses bens, constituindo-se assim meio eficaz para a divulgação do conhecimento produzido pela arqueologia. Para Manzato (2005, p.44), o turismo arqueológico ou arqueoturismo:

Consiste no processo decorrente de deslocamento e da permanência de visitantes a locais denominados sítios arqueoturísticos, onde são encontrados os vestígios remanescentes de antigas sociedades, sejam elas préhistóricas e/ou históricas, passíveis de visitação terrestre ou aquática.

Dessa forma, percebe-se que o turismo arqueológico é um segmento cujos atrativos são os vestígios arqueológicos deixados pelas civilizações passadas, que estimulam o interesse das pessoas em conhecer os locais onde encontram-se disponíveis. É válido destacar na conceituação de Manzato (2005) que o turismo arqueológico também pode ser denominado de arqueoturismo, referindo-se assim a uma terminologia utilizada para simplificar o segmento.

É pertinente observar ainda que nas definições apresentadas anteriormente sobre turismo arqueológico os autores mencionam os termos sítios arqueoturísticos e sítios arqueológicos. Ressalta-se, entretanto, que não são sinônimos. Os sítios arqueológicos podem ser definidos de acordo com Horta, Grumberg, e Monteiro (1999, p.32) como os lugares "onde se encontram os vestígios da vida e da cultura material dos povos passados". Dessa forma, conforme Manzato (2005) no momento em que esses sítios são disponibilizados para visitação é que passam a se chamar sítios arqueoturísticos.

Outra definição encontrada para este segmento é apresentada por Widmer (2009, p.69), que o define como:

Um segmento de turismo no qual ocorre o deslocamento voluntário e temporário de indivíduos, motivados pelo interesse ou desejo de conhecimento de aspectos pertinentes a culturas passadas, a locais onde se encontram vestígios materiais representativos do processo evolutivo do homem no planeta, deixados por sociedades pretéritas. 
Logo, percebe-se que o turismo arqueológico promove por meio da visitação o contato com a cultura dos povos primitivos, e possibilita ao turista ou visitante satisfazer a necessidade de estar em contato com o passado. Dentre os principais tipos de sítios arqueológicos existentes, pode-se citar, conforme Ries (2003); Figueiredo e Pereira (2007):

-Acampamento - caracteriza-se como local de permanência temporária;

-Cemitério - sítio onde se encontram evidências de sepultamentos;

- Cerâmico - local onde o material cerâmico é a principal evidência;

-Cerimonial - lugar onde se encontram evidências de práticas religiosas ou sociais;

-Sítio colonial - sítio cujos vestígios são atividades do período colonial;

-Habitação - sítio caracterizado pelo tempo de permanência prolongada.

-Sambaqui - sítio arqueológico cuja composição predominante são conchas. Podem chegar até 30 metros de altura e apresentam-se sob a forma de uma pequena coluna arredondada, composta quase exclusivamente por carapaças de moluscos.

-Arte rupestre - caracteriza-se pela predominância de inscrições (pinturas ou gravuras) as quais foram deixadas pelo homem em paredes de abrigos, grutas, entre outros.

Diante do exposto, observa-se a diversidade de sítios arqueológicos existentes com características peculiares que estimulam a curiosidade, 0 desejo em conhecê-los. O elemento motivador nesses locais é o patrimônio arqueológico o qual se refere a uma categoria do patrimônio cultural que será tratado a seguir, estabelecendo assim a sua relação com o turismo.

Em relação ao Estado do Rio Grande do Norte, este é um Estado com uma expressiva representatividade de sítios arqueológicos, sendo, portanto com potencial para o desenvolvimento do turismo arqueológico. De acordo com o IPHAN (2011) encontram-se no sistema de Cadastro Nacional de Sítios Arqueológicos (CNSA) 281 sítios arqueológicos no Rio Grande do Norte. Esse número oficial ainda é baixo diante da diversidade de sítios existentes no Estado que ainda não foram catalogados.

Dentre os municípios do Estado do Rio Grande do Norte, oficialmente registradas pelo IPHAN com a maior quantidade de sítios arqueológicos identificados estão: Carnaúba dos Dantas (37); Mossoró (16); Santana do Matos (13); Tibau do Sul, Nísia Floresta e Maxaranguape (09); Areia Branca (07) e São José de Mipibú (06) (IPHAN, 2011).

O município de Carnaúba dos Dantas está localizado no Estado do Rio Grande do Norte, na mesorregião Central Potiguar e na microrregião Seridó Oriental, a uma distância de $230 \mathrm{~km}$ da capital, do Estado, município de Natal. A população atual existente no município de Carnaúba dos Dantas é de 7.429 habitantes. O bioma predominante é a caatinga e o clima semiárido. A economia dos municípios baseia-se principalmente em atividades como a agropecuária, extrativismo e comércio IBGE (2010); IDEMA (2011); CPRM (2005).

Observa-se que o município de Carnaúba dos Dantas vem despontando no cenário do turismo arqueológico a nível estadual como um 
dos portadores da maior quantidade de sítios arqueológicos registrados pelo IPHAN até o momento, demonstrando um potencial expressivo para a prática desse segmento. Sendo assim, apresenta-se a seguir de forma mais detalhada nesse estudo a região do Seridó Potiguar e o seu potencial para o desenvolvimento do turismo arqueológico.

De acordo com Azevedo (2007), o Seridó Potiguar é composto por 23 municípios, localiza-se na Mesoregião Central do Rio Grande do Norte, mais especificamente na porção meridional do Estado, e corresponde ao que hoje - IBGE considera como as microrregiões do Seridó Oriental e Seridó Ocidental, e a Microregião de Serra de Santana, excluindo-se os municípios de Santana dos Matos e Bodó.

A Figura 1 apresenta a região do Seridó Potiguar com seus limites políticos, malha viária rodoviária, recursos hídricos, além dos principais sítios geológicos da região. Apesar de o mapa identificar os sítios geológicos, é válido destacar que os elementos geológicos se complementam com os arqueológicos uma vez que as incisões e as pinturas de arte rupestre estão localizadas nas formações rochosas.

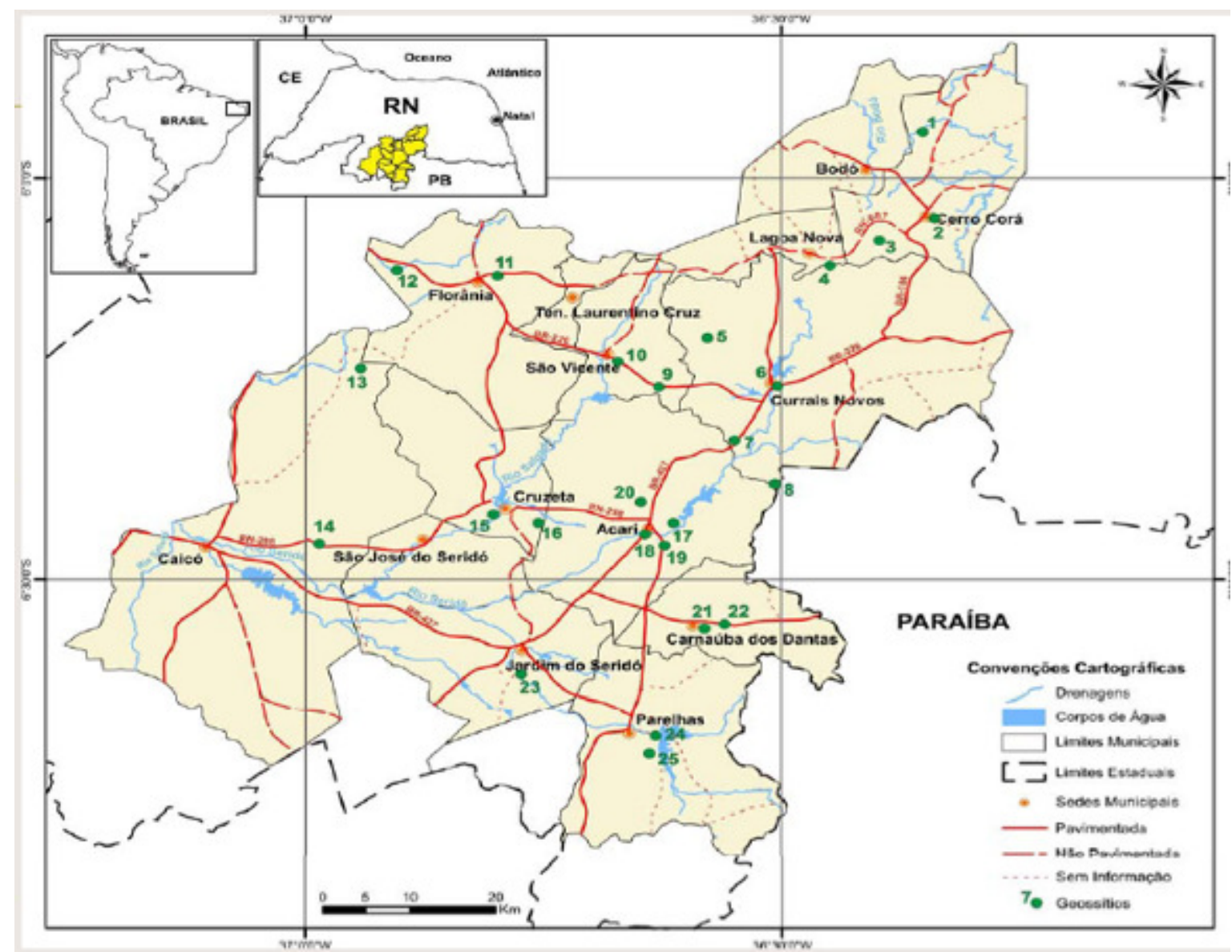

Figura 1: Localização dos principais geosítios do Seridó Potiguar. Figure 1: Location of main geosites in Seridó Potiguar.

Fonte: Nascimento (2010).

Source: Nascimento (2010). 
De acordo com o IPHAN (2011) foram cadastrados na região do Seridó Potiguar 55 sítios arqueológicos localizados em vários municípios, dentre eles: Carnaúba dos Dantas (37); Tenente Laurentino Cruz (06); Parelhas, Serra Negra do Norte e Florânia (04); Acari, Caicó e São João do Sabugi (03); Jucurutu e Timbaúba dos Batistas (02); São Fernando e Equador (01); Cruzeta (02). Nesse sentido, percebe-se que a maior concentração de sítios arqueológicos localiza-se no município de Carnaúba dos Dantas, considerado como referência no desenvolvimento do turismo arqueológico nessa região. Dentre os principais sítios arqueológicos existentes no município de Carnaúba dos Dantas, destacam-se: o sítio Pedra do Alexandre, Xique-Xique I e Xique-Xique II.

Observa-se que há um maior potencial do município de Carnaúba dos Dantas para o desenvolvimento do turismo arqueológico na região. Os sítios mencionados e outros existentes na localidade recebiam visitas de moradores locais, turistas e estudantes, de forma desordenada, ou seja, sem planejamento, estrutura para disponibilizar a visitação de forma adequada. Nesse sentido, o IPHAN, ao identificar a relevância dos sítios arqueológicos existentes no município, realizou investimentos destinados à socialização e regularização do uso turístico de dois sítios em Carnaúba dos Dantas: Xique-Xique I e II.

De acordo com o IPHAN (2011), o investimento total nesses sítios foi de $R \$ 180$ mil reais (cerca de US\$ 85 mil dólares americanos), destinados a instalações de escadarias; trilhas; áreas de descanso; plataformas de madeira de lei para visualização das pinturas rupestres, entre outros. A inauguração das obras e serviços realizados pelo IPHAN nos sítios XiqueXique I e II ocorreu no dia 28 de março de 2011.

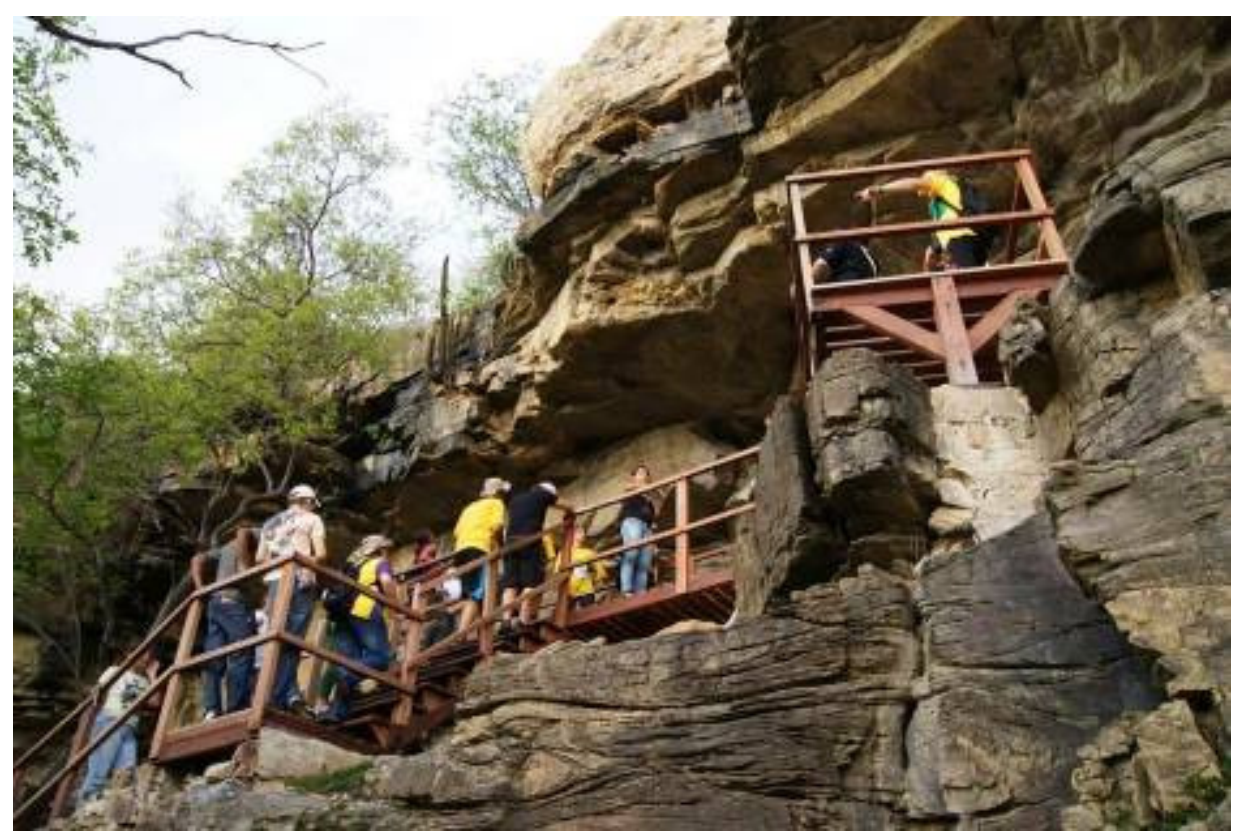

Figura 2: Passarela suspensa no Sítio Xique-Xique 1.

Figure 2: Suspended walkway on the Site Xique Xique-1.

Fonte: Nóbrega (2012).

Source: Nóbrega (2012). 


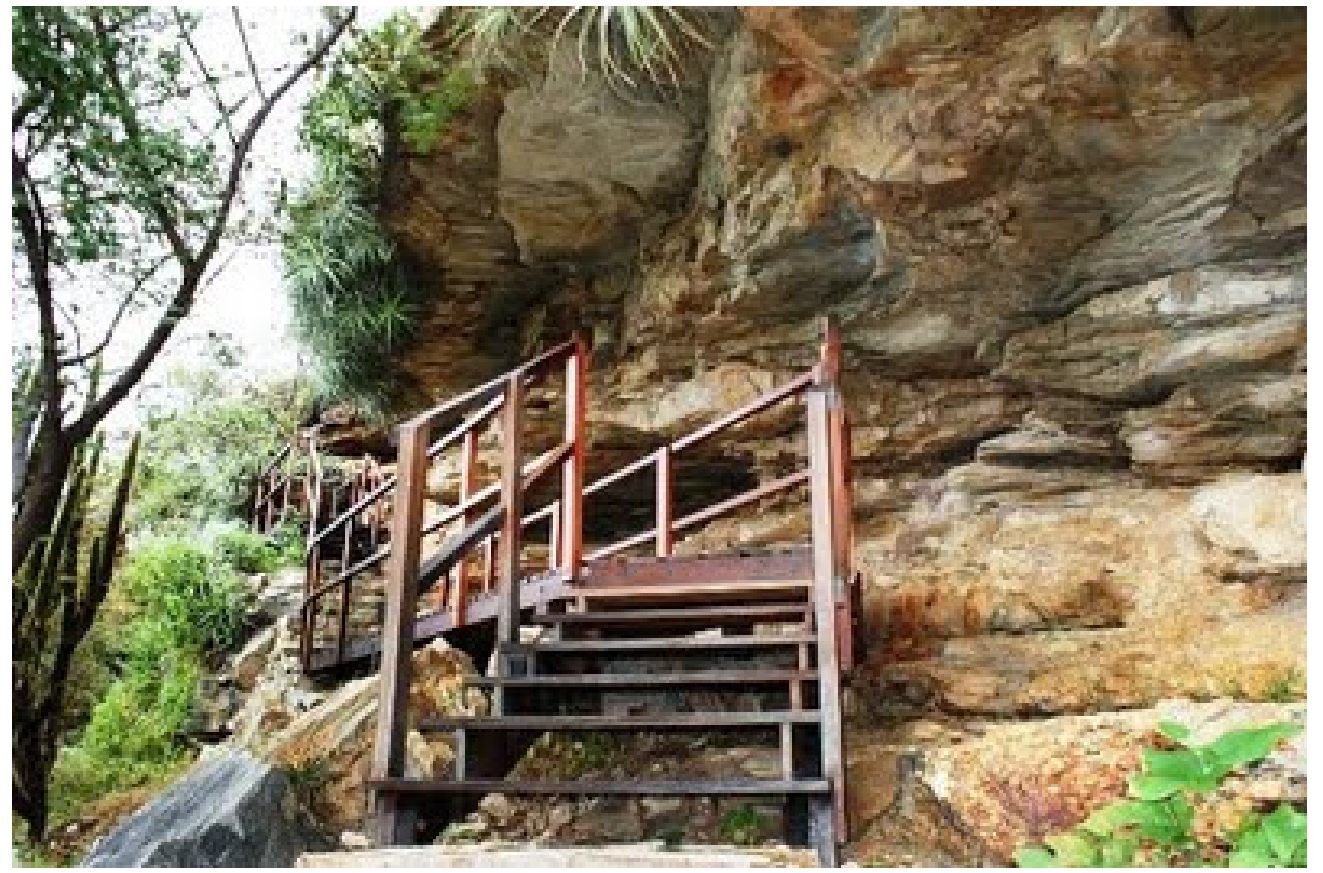

Figura 3: Passarela suspensa no Sítio Xique-Xique 2.

Figure 3: Suspended walkway on the Site Xique Xique 2.

Fonte: Nóbrega (2012).

Source: Nóbrega (2012).

Martin (2008), Monteiro (2000), e Pessis (1992) publicaram importantes documentos que retratam as classificações dos registros rupestres na região do Seridó Potiguar divididas em Tradição Nordeste; Tradição Agreste e Tradição Itacoatiara. A primeira é destacada pela presença de figuras antropomorfas pequenas, isto é, figuras que destacam o plano biológico do ser humano.

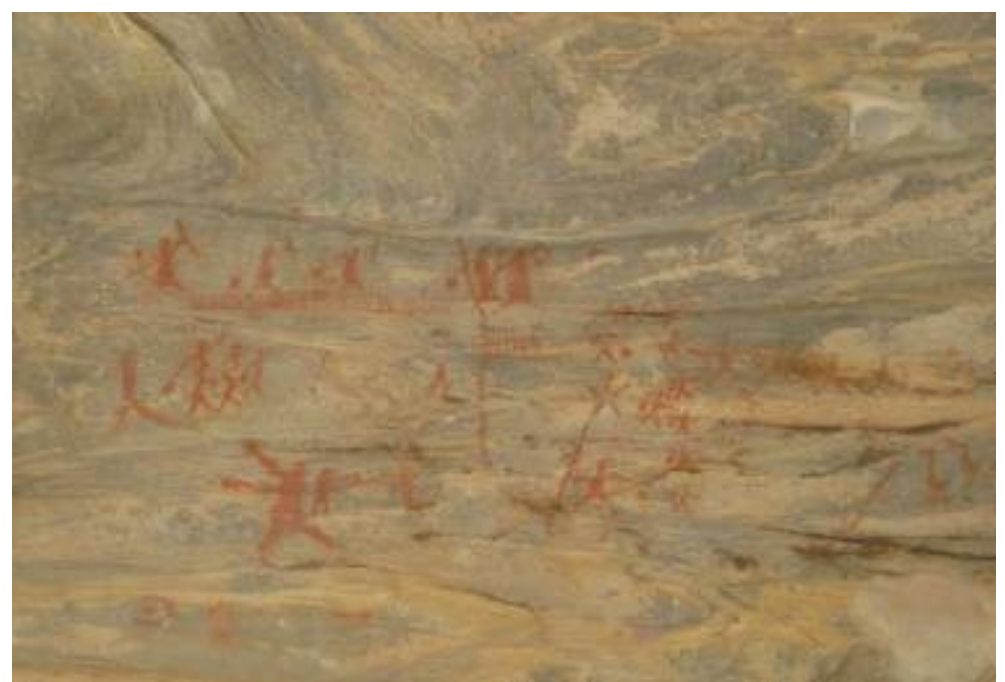

Figura 4: Pinturas rupestres de Tradição Nordeste em Carnaúba dos Dantas. Figure 4: Nordeste Tradition of rock paintings in Carnaúba dos Dantas.

Fonte: Nóbrega (2012).

Source: Nóbrega (2012). 


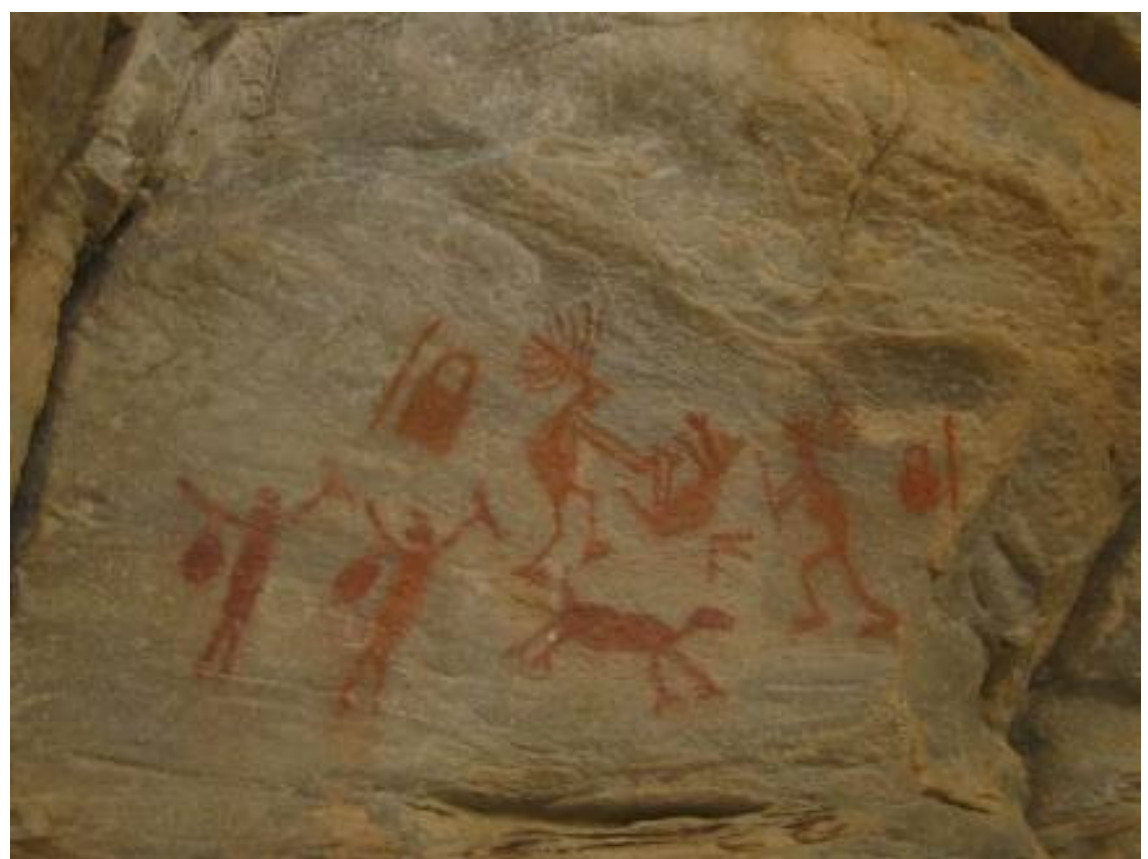

Figura 5: Pinturas rupestres de Tradição Agreste em Carnaúba dos Dantas. Figure 5: Agreste Tradition of rock paintings in Carnaúba dos Dantas.

Fonte: Nóbrega (2012).

Source: Nóbrega (2012).

As Figuras 4 e 5 representam cenas lúdicas, práticas sexuais, caças, danças e de violência. Além dos aspectos antropomorfos também é possível observar as figuras zoomorfos (animais quadrúpedes). A tradição Agreste caracteriza-se pela predominância dos grafismos que representam basicamente as figuras humanas em momentos de caça. Não há um conjunto de figuras que caracterizam um movimento. Finalmente, a Tradição Itacoatiara caracteriza-se pelas incisões nas rochas, e não com pinturas. As incisões representam grafismos puros e encontram-se basicamente ao longo do leito dos recursos hídricos, como rios, cachoeiras e lagos.

\section{Apresentação dos resultados}

A pesquisa de campo consistiu em entrevistas realizadas com os envolvidos (poder público municipal, poder público estadual, IPHAN) no total de 6 entrevistas; além de 14 entrevistas realizadas com as comunidades do entorno dos sítios arqueológicos Xique Xique I e II, totalizando 20 entrevistas.

A partir do levantamento e tratamento dos dados foi possível identificar algumas possibilidades e entraves para o desenvolvimento do turismo arqueológico na área em estudo no qual foram sistematizados no Quadro 1, conforme exposto à seguir. 
Quadro 1: Possibilidades e entraves identificados durante a pesquisa

Table 1: Possibilities and challenges identified during the research

\section{POSSIBILIDADES}

\begin{tabular}{|c|c|}
\hline $\begin{array}{l}\text { Potencialidades turísticas existentes nos sítios } \\
\text { (Paisagens, registros rupestres, vegetação, } \\
\text { recursos hídricos); }\end{array}$ & $\begin{array}{l}\text { Dificuldade de acesso aos locais } \\
\text { principalmente no período chuvoso; }\end{array}$ \\
\hline $\begin{array}{l}\text { Interesse do poder público em estabelecer } \\
\text { parcerias com outros órgãos; }\end{array}$ & $\begin{array}{l}\text { Inexistência de uma política pública voltada } \\
\text { para o fomento do turismo arqueológico } \\
\text { municipal, estadual, e federal; }\end{array}$ \\
\hline $\begin{array}{l}\text { Interesse da casa de cultura pelo } \\
\text { desenvolvimento do turismo arqueológico nos } \\
\text { municípios; }\end{array}$ & $\begin{array}{l}\text { Inexistência de uma secretaria municipal } \\
\text { ligada ao desenvolvimento turístico na } \\
\text { maioria dos municípios da região; }\end{array}$ \\
\hline $\begin{array}{l}\text { Interesse do IPHAN em desenvolver estudos } \\
\text { aprofundados nos sítios; }\end{array}$ & $\begin{array}{l}\text { Orçamento público insuficiente para arcar } \\
\text { com os investimentos para implementação } \\
\text { do turismo arqueológico no município; }\end{array}$ \\
\hline $\begin{array}{l}\text { Interesse das comunidades do entorno em } \\
\text { desenvolver o turismo arqueológico nas } \\
\text { localidades; }\end{array}$ & $\begin{array}{l}\text { Inexistência de uma legislação municipal de } \\
\text { proteção ao patrimônio; }\end{array}$ \\
\hline $\begin{array}{l}\text { O turismo como ferramenta para a conservação } \\
\text { do patrimônio arqueológico existente nas } \\
\text { localidades; }\end{array}$ & $\begin{array}{l}\text { Falta de articulação no âmbito cultural e do } \\
\text { turismo nos municípios com os órgãos } \\
\text { estaduais e federais; }\end{array}$ \\
\hline \multirow[t]{4}{*}{$\begin{array}{l}\text { O desenvolvimento do turismo arqueológico } \\
\text { seria uma possibilidade de ampliação de fonte } \\
\text { de renda para as comunidades do entorno. }\end{array}$} & $\begin{array}{l}\text { Ausência de recursos humanos qualificados } \\
\text { para atuarem no desenvolvimento do } \\
\text { turismo arqueológico; }\end{array}$ \\
\hline & $\begin{array}{l}\text { Inexistência de transportes regulares ou } \\
\text { particulares aos sítios arqueológicos; }\end{array}$ \\
\hline & $\begin{array}{l}\text { Desinteresse de parte dos proprietários em } \\
\text { desenvolver o turismo arqueológico nos } \\
\text { sítios arqueológicos }\end{array}$ \\
\hline & $\begin{array}{l}\text { Falta de conhecimento dos proprietários } \\
\text { acerca da relevância do patrimônio } \\
\text { disponível em suas terras. }\end{array}$ \\
\hline
\end{tabular}

Fonte: Araújo (2012).

Source: Araújo (2012).

Como pode ser observado no Quadro 1 foram identificadas algumas possibilidades e entraves para o desenvolvimento do turismo arqueológico no município de Carnaúba dos Dantas. É pertinente ressaltar que além dos entraves elencados no quadro apresentado, consideram-se também como fatores os quais dificultam o desenvolvimento do turismo nos municípios citados. Para Nóbrega (2012) e Figueiredo et. al. (2012), o produto turístico requer uma articulação de muitos fatores. Isso nos mostra que o turismo utiliza-se de toda e qualquer informação do núcleo receptor (cidade ou local que recebe os turistas). Para o autor, tudo que o núcleo detiver como atrativos, infraestrutura (como água encanada, energia elétrica, ou acesso), história do lugar, podem ser motivadores da viagem. O elemento atrativo é o principal componente, pois sem ele não há a motivação de visitar um determinado local, porém também é de extrema importância à disponibilidade dos sistemas de transportes, serviços gerais, coleta de lixo, rede de esgotos, serviços de entretenimento e serviços de hospedagem. Em síntese, o produto turístico deve ter cinco componentes básicos conforme apontado por Ansarah (2001): $1^{\circ}$ ) atrativos; $2^{\circ}$ ) facilidades, instalações e serviços; $3^{\circ}$ ) acessos; $4^{\circ}$ ) imagens que os turistas detêm do local a ser visitado e, finalmente, $\left.5^{\circ}\right)$ preço. 
Diante desse cenário, faz-se necessário aplicar um conjunto de ações de planejamento que poderiam otimizar o uso dos recursos turísticos representados principalmente pelas pinturas e gravuras rupestres dos sítios arqueológicos, associado à ações de conservação e preservação do patrimônio arqueológico existente, que poderiam ao mesmo tempo manter o patrimônio, através da memória e história dos povos que habitaram a região como também proporcionar um acréscimo de renda às populações residentes no entorno dos sítios pesquisados através de pequenos estabelecimentos comerciais que dessem suporte tanto de hospedagem quanto de serviços de restauração com oferta de produtos da gastronomia sertaneja.

O fato de a comunidade ser favorável à implementação do turismo arqueológico nas comunidades do entorno dos sítios é extremamente importante que o processo de planejamento tenha uma conotação participativa. De acordo com Barreto (2005, p. 20), "a comunidade deve ter direito de pronunciar-se inclusive sobre o não-desenvolvimento do turismo em determinado local".

O interesse do IPHAN em desenvolver estudos mais aprofundados nos sítios pesquisados é relevante para a implementação do turismo arqueológico nas localidades, pois, fornecerá informações mais precisas sobre o patrimônio arqueológico existente, como por exemplo, a datação, o estilo, tradição e sub-tradição aos quais os registros rupestres encontrados pertencem, além de efetivar o cadastramento dos sítios no Cadastro Nacional de Sítios Arqueológicos (CNSA) possibilitando assim 0 conhecimento da existência de diversos sítios arqueológicos na região do Seridó Potiguar, e consequentemente uma possibilidade do investimento de recursos nos sítios.

Identificou-se como entraves para o desenvolvimento do turismo arqueológico nas comunidades do entorno a inexistência de uma política pública voltada para o fomento do turismo no município e orçamento público insuficiente para arcar com os investimentos voltados ao turismo arqueológico. Além disso, a inexistência de uma legislação de proteção ao patrimônio no município demonstra a falta de atenção e interesse do poder público pela conservação e preservação do patrimônio cultural local. De acordo com um funcionário da prefeitura de Carnaúba dos Dantas, o poder público municipal teria interesse em estabelecer parcerias com outros órgãos para desenvolver o turismo arqueológico. Nesse sentido, considerase uma possibilidade para a implementação do segmento nas localidades estudadas, visto que o poder público não possui recursos financeiros suficientes para arcar individualmente com investimentos dessa natureza, mas, está disposto para o estabelecimento de parcerias com outros órgãos, conforme apontado pelo funcionário da prefeitura.

A ausência de recursos humanos qualificados na localidade em estudo também é um entrave para o desenvolvimento do turismo na área, pois como foi identificado durante a pesquisa o grau de escolaridade das comunidades do entorno é baixo, a maioria possui apenas o ensino fundamental incompleto. 
Dentre todos os entraves apresentados no quadro 1 considera-se como o principal impedimento para o desenvolvimento do turismo arqueológico nos sítios arqueológicos a falta de conhecimento dos proprietários sobre a relevância do patrimônio disponível em suas terras, o que faz com que os mesmos não tenham interesse em desenvolver o turismo arqueológico na localidade, optando por utilizar o espaço para a prática econômica voltada principalmente à pecuária.

\section{Considerações finais}

O turismo arqueológico é um segmento que vem se destacando em cenário mundial, alcançando um notável crescimento nos últimos anos, o qual pode ser percebido pela quantidade de sítios arqueológicos disponíveis para visitação, não estando mais restrito a países como Grécia ou Egito.

Foi observado neste trabalho que há uma estreita relação entre a arqueologia e o turismo, além disso, é destacado em âmbito mundial o papel que o turismo arqueológico pode desempenhar no desenvolvimento regional desde que seja incorporado no planejamento das agendas públicas municipais, estaduais e federais, não apenas como uma ferramenta ao desenvolvimento econômico, mas como um recurso de valorização cultural dos povos da sociedade seridoense potiguar, pois o turismo arqueológico quando planejado de forma adequada pode ser uma alternativa para a proteção do patrimônio arqueológico, tendo em vista que poderá dar um uso social por meio da promoção do seu acesso ao público em geral.

A região do Seridó Potiguar detém um expressivo potencial para 0 desenvolvimento do turismo arqueológico, destacando-se o município de Carnaúba dos Dantas pela grande quantidade de sítios arqueológicos, dentre os quais, os sítios Xique Xique I e II foram dotados de infraestrutura pelo IPHAN com a finalidade de promover a socialização do patrimônio arqueológico existente nos mesmos. Nesse sentido, percebe-se que a proposta de turismo arqueológico deve partir do princípio de que seja estimulado o acesso às visitas ao patrimônio arqueológico existente em sítios arqueológicos, sejam eles terrestres ou aquáticos, a fim de que o público tenha cada vez mais acesso ao patrimônio, pois a conservação depende do conhecimento difundido entre os diferentes atores da sociedade.

Por outro lado, é importante destacar que para ocorrer o desenvolvimento do turismo não basta apenas a existência de atrativos na região. São necessários esforços de uma série de ações como infraestrutura básica e turística, promoção, treinamento profissional através de cursos ligados ao setor turístico, e articulações políticas integradas no âmbito regional.

A pesquisa apontou diversos fatores que impossibilitam 0 desenvolvimento do turismo nos municípios pesquisados. Dentre os mais significativos estão: orçamento público insuficiente para arcar com os investimentos de implementação do turismo arqueológico nos municípios; inexistência de uma legislação municipal de proteção ao patrimônio; ausência de recursos humanos qualificados nos municípios; e a falta de 
conhecimento e informação dos proprietários sobre a relevância do patrimônio disponível em suas terras.

Além disso, dentre as medidas necessárias para o desenvolvimento do turismo arqueológico é fundamental que seja desenvolvida nos municípios uma política voltada para o turismo e a valorização do patrimônio; que haja uma maior articulação no âmbito da cultura e do turismo nos municípios com os órgãos estaduais e federais a fim de estabelecer parcerias, pois o poder público não possui recursos financeiros suficientes para arcar independentemente com investimentos dessa natureza.

Uma possibilidade para o desenvolvimento deste segmento turístico seria a implantação de projetos e estudos que incentivem a cultura, a valorização do patrimônio arqueológico para aproximá-lo do público. Para isso, seria importante ações voltadas à educação patrimonial, pois, por meio desta ação seria possível sensibilizar a comunidade local e o público externo, o poder público e os proprietários dos sítios arqueológicos sobre a importância da conservação do patrimônio e para a manutenção da identidade local, o que consequentemente poderia estimular o engajamento coletivo pela conservação dos recursos arqueológicos existentes nos sítios.

Finalmente, acredita-se que caso não haja a implementação de ações concretas voltadas ao desenvolvimento turístico na região do Seridó Potiguar, pode-se acompanhar uma substituição ou ampliação do investimento de outros setores da economia com maior poder de degradação ambiental, como a extração madeireira e a mineração, apenas para explicitar algumas. Também é importante trabalhar numa perspectiva coletiva entre os diferentes atores regionais ligados ao setor turístico, com iniciativas que possam integrar o uso dos recursos turísticos e investimentos em infraestrutura básica e turística que possam atender um interesse da região como um todo e não apenas ações pontuais que geralmente contemplam interesses de uma elite local em detrimento de ações do uso e benefícios econômicos coletivos.

\section{Referências bibliográficas}

AZEVEDO, F.F. Entre a Cultura e a Política: uma Geografia dos currais no sertão do Seridó. Tese de doutoramento do programa de pós graduação em geografia. Universidade Federal de Uberlândia. Uberlândia, 2007.

BARRETTO, M.; REJOWSKI, M. Considerações epistemológicas sobre segmentação: das tipologias turísticas à segmentação de mercado. In: NETTO PANOSSO, A.; ANSARAH, M.G. (Orgs.). Segmentação do mercado turístico: estudos, produtos e perspectivas. Manole, Barueri, p. 03-18, 2009.

BARRETO, M. Turismo e Legado Cultural: As possibilidades do planejamento. Campinas: Papirus, 2000.

BRASIL. MINISTÉRIO DA JUSTIÇA. Constituição Federal de 1988. Disponível

em: $<$ http://www.alep.pr.gov.br/system/files/corpo/Con1988br.pdf>. Acesso em: 10 out. 2010. 
BRASIL. MINISTÉRIO DA JUSTIÇA. Decreto lei 107, de 8 de setembro de 2001. Disponível em: <http://ceam.pt/wp-content/uploads/2009/02/107 2001.pdf> Acesso: 31 de Out. 2009.

BRASIL. MINISTÉRIO DA JUSTIÇA. Decreto lei 3.924 de 26 de Julho de 1961. Disponível em: <http://www.planalto.gov.br/civil03/leis/19501969/L3924.htm>. Acesso em 24 de set. 2012.

BRASIL. MINISTÉRIO DA JUSTIÇA. Decreto lei 3.551 de 4 de agosto de 2000. em: $<$ http:/www.planalto.gov.br/ccivil 03/decreto/D3551.htm >. Acesso em: 20 ago. 2012.

CHAUI, M. Cultura e democracia: crítica y emancipación. Revista Latino Americana de Ciências Sociales. v. 1. n. 1, p. 53-76, 2008.

CORREA, R.L. Região e organização espacial. São Paulo: Ática, 1986.

FIGUEIREDO, S.J.L.; PEREIRA, E. Turismo e Arqueologia na Amazônia Brasil: aspectos de preservação e planejamento. In: Seminário da Associação Nacional de Pesquisa e Pós-graduação em Turismo, 4. 2007, São Paulo. Anais... São Paulo: Anptur/Universidade Anhembi-Morumbi, 2007. v. 1, p. 235-250. Disponível em: $<$ http://www.scielo.br/scielo.php?pid=S1981-

81222009000100014 ...sci... .Acesso em: 2 set. 2012.

FIGUEIREDO, S.J.L. et al. Planificación y Gestión de las Visitas al Patrimonio Natural y Cultural y a los Atractivos Turísticos. Estudios y Perspectivas en Turismo, v. 21, p. 355-371, 2012.

FIGUEIREDO, S.J.L. Viagens e viajantes. São Paulo: AnnaBlume, 2010.

FUNARI, P.P. Arqueologia. São Paulo: 1998.

FUNARI, P.P.; PINSKY, J. Turismo e patrimônio Cultural. Contexto: São Paulo, 2005.

HORTA, M.L.P.; GRUMBERG, E.; MONTEIRO, A.Q. Guia básico de educação patrimonial. Instituto do Patrimônio Histórico e Artístico Nacional. Brasília: Museu Imperial, 1999.

INSTITUTO BRASILEIRO DO MEIO AMBIENTE E DOS RECURSOS NATURAIS RENOVÁVEIS (IBAMA). Parque Nacional Sete Cidades. Disponível em: <www.ibama.gov.br/revista/7cida/texto 7cida.htm >. Acesso em: 22 set.2014.

INSTITUTO BRASILEIRO DE GEOGRAFIA E ESTATÍSTICA (IBGE). Histórico de Carnaúba dos Dantas. Disponível em: $<$ http://www.cidades.ibge.gov.br/painel/historico.php?lang=\&codmun=24024 0\&search $=\mid$ infogr\%E1ficos:-hist\%F3rico > . Acesso em: 12 de set. 2014.

INSTITUTO DE DESENVOLVIMENTO SUSTENTÁVEL DO RN (IDEMA). (2010) Perfil do seu Município: Carnaúba dos Dantas. Disponível em:<www.idema.rn.gov.br/.../idema/perfil/Parelhas/>. Acesso em: 25 ago. 2014. 
INSTITUTO DO PATRIMÔNIO HISTÓRICO ARTÍSTICO NACIONAL (IPHAN). Banco de Dados. Disponível em: $<$ portal.iphan.gov.br/portal/montarPaginaSecao.do?id...paginalphan>.

Acesso em: 22 set. 2012.

INSTITUTO DO PATRIMÔNIO HISTÓRICO ARTÍSTICO NACIONAL (IPHAN). Inauguração de obras nos sítios arqueológicos de xiquexique (RN).

Disponível em:<http://portal.iphan.gov.br/portal/montarDetalheConteudo.do;jsessionid=9 FA94C4F5833132CEBA60DCCA6047991?id=15900\&sigla=ItemAgenda\&ret orno=detalheltemAgenda.. . Acesso em: 23 set. 2012.

MACEDO, H.A.M.; BRITO, P.S. Pedra do Alexandre II. História do RN. Disponível em: <.www.seol.com.br/rnnaweb/historia/prehistoria/>. Acesso em: 24 set.2012.

MANZATO, F.; REJOWSKI, M. Turismo Arqueológico no estado de São Paulo. Revista patrimônio (online), nov.2005. Disponível em: $<$ http://www.unisantos.br/pos/revistapatrimonio/artigos.php?cod=46>.

Acesso em: 13 out. 2012.

MARTIN, G. Pré-História do Nordeste do Brasil. Recife: Ed. Universitária da UFPE, 2008.

NASCIMENTO, M.A.L. Patrimônio Geológico e Geoturismo. In: PFALTZGRAFF, P.A.S.; TORRES, F.S.M. (Orgs.). Geodiversidade do Estado do Rio Grande do Norte. Rio de Janeiro: CPRM, p. 133-144, 2010.

MONTEIRO, D.M. Introdução à história do Rio Grande do Norte. Natal, 2008.

NÓBREGA, W.R.M. Turismo e políticas públicas na Amazônia brasileira: instâncias de governança e desenvolvimento nos municípios de Santarém e Belterra, oeste do estado do Pará. Tese de doutoramento do programa de Pós Graduação em Desenvolvimento Sustentável do Trópico Úmido. Belém: UFPA/PPGDSTU/NAEA, 2012.

PERROUX, F. A economia do século XX. Lisboa: Morais, 1967.

PESSIS, A.M.; GUIDON, N. Registros rupestres no Nordeste do Brasil: estado atual da pesquisa. São Paulo: Nobel, p. 19-34, 1992.

RIES, G. Arqueologia: um potencial para o ecoturismo no Brasil. Serra da Capivara, um exemplo a ser seguido. São Paulo: SENAC, 2003.

SANTOS, M. Espaço e método. São Paulo: Edusp, 2008.

SCATAMACCHIA, M.C.M. Turismo e arqueologia. São Paulo: Aleph, 2005.

SILVA, A.C.S. Representações sociais sobre o patrimônio histórico de Belém (PA): Estudo de caso sobre a igreja das mercês e seu entorno. In: FIGUEIREDO, S. L. (org). Turismo, lazer e planejamento urbano e regional. Belém: NAEA, p. 39-58, 2008.

WIDMER, G. M. Turismo arqueológico. In: PANOSSO NETO, A.; ANSARAH, M.G. R. (Orgs.). Segmentação do mercado turístico: estudos, produtos e perspectivas. Barueri: Manole, p. 67-88, 2009. 
Wilker Ricardo de Mendonça Nóbrega: Universidade Federal do Rio Grande do Norte, Natal, RN, Brasil.

E-mail: wilkernobrega@yahoo.com.br

Link para o currículo Lattes: http://lattes.cnpq.br/0025142529544906

Francineide Araújo: Universidade Federal do Rio Grande do Norte, Natal, RN, Brasil.

E-mail: francyturismologa@hotmail.com

Link para o currículo Lattes: http://lattes.cnpq.br/1372382921462251

Data de submissão: 30 de outubro de 2014

Data de recebimento de correções: 22 de dezembro de 2014

Data do aceite: 22 de dezembro de 2014

Avaliado anonimamente 